\title{
O Grêmio da Paulista e o lazer do ferroviário rio-clarense
}

\author{
Américo Valdanha Netto ${ }^{1}$ \\ Samuel de Souza Neto ${ }^{2}$ \\ Dagmar Aparecida Cynthia França Hunger ${ }^{3}$ \\ ${ }^{1}$ UNIESP - ISEP, São Sebastião do Paraíso, MG, Brasil \\ ${ }^{2}$ Instituto de Biociências. UNESP - Univ Estadual Paulista, Campus de Rio Claro, \\ Departamento de Educação, Rio Claro, SP, Brasil \\ ${ }^{3}$ Faculdade de Ciências. UNESP - Univ Estadual Paulista, Campus de \\ Bauru,Departamento de Educação Física, Bauru, SP, Brasil
}

\begin{abstract}
Resumo: Este artigo resgata a memória de um passado não muito distante, para investigar os indícios do desenvolvimento de uma cultura de lazer no Município de Rio Claro, evidenciada no Grêmio Recreativo dos Empregados da Companhia Paulista de Estradas de Ferro (GRECPEF), identificando as atividades de lazer dos ferroviários e a relação dessas com o clube. Para as pretensões da pesquisa foi utilizado um modelo de investigação de natureza exploratória, tendo como foco as relações do GRECPEF com a história social da cidade de Rio Claro. Os dados foram coletados através de revisão bibliográfica e de entrevistas semi-estruturadas, realizadas com ferroviários aposentados, que fazem parte do quadro de sócios do grêmio. No âmbito desse contexto pode-se constatar que o clube é referência para as atividades de lazer do trabalhador ferroviário, e tem significativa importância e influência na construção de uma cultura de lazer na cidade.
\end{abstract}

Palavras-chave: História do Esporte. Lazer e Ferroviário. Clube Esportivo. Lazer do Trabalhador.

\section{"Paulista" club and leisure of Rio Claro citizen railway workers}

\begin{abstract}
This article turns to the memory of a not too distant past, to investigate the cultural leisure evidence and its development in the city of Rio Claro which has been shown by the Recreation Club Employee of the Companhia Paulista de Estradas de Ferro (GRECPEF), identifying the leisure activities and the relation of these railway employee with the club. For the claims of the research an exploratory investigative model had been used focusing the relationship of GRECPEF with the social history of the city of Rio Claro. Data had been collected through literature review and semi-structured interviews with railway retire employee, who are part of the partner board of the Recreation Club. Within this context one can see that this club is a reference to the leisure activities of the railway employee, and has significant importance and influence on the setting up of a leisure culture in the city.
\end{abstract}

Key Words: Sport History. Leisure and Railway Employee. Sports Club. Employee's leisure.

\section{Introdução}

O Município de Rio Claro foi e é objeto de estudo para historiadores, sociólogos e cientistas políticos de abrangência nacional e internacional, como Garcia (1992), Dean (1977), Diniz (1973), Tenca (2002), Marrach (1983), Bilac (1978), Queiroz (1986) e Santos (2002). Entretanto, esses são trabalhos que tiveram como recorte particularidades da cidade, analisando seu desenvolvimento social e urbano, principalmente quando comparado com outros Municípios ou Regiões do país, através de estudos referentes ao período cafeeiro e o desenvolvimento da Companhia Paulista de Estradas de Ferro (CPEF).

Embora haja produção acadêmica referente à história social e política da cidade em sua literatura histórica, há uma lacuna quando se buscam estudos sobre o esporte na cidade em geral, ou que tratem das atividades de lazer do trabalhador rio-clarense. Esta questão se torna ainda mais significativa quando se contempla a realidade do trabalhador da Companhia Paulista de Estradas de Ferro (CPEF) e a importância do Grêmio Recreativo dos Empregados da Companhia Paulista de Estradas de Ferro (GRECPEF) nas atividades do tempo livre dos trabalhadores da empresa.

Dessa forma, no presente artigo, objetivou-se investigar, de maneira exploratória, as relações entre a Companhia Paulista de Estradas de Ferro (CPEF), o Grêmio Recreativo dos Empregados da Companhia Paulista de Estradas de Ferro (GRECPEF), as atividades de lazer dos 
trabalhadores da CPEF e a relação do GRECPEF com o Município de Rio Claro.

\section{Métodos}

Devido à própria natureza pioneira do estudo, uma metodologia baseada na pesquisa exploratória apresentou-se como a melhor opção para nortear os trabalhos, considerando o pouco conhecimento acumulado e sistematizado a respeito do assunto. Segundo Selltiz et al (1967), em estudos exploratórios a ênfase acontece com descobertas de idéias e de intuições, que têm por objetivo a familiarização com o fenômeno, ou conseguir nova compreensão deste, freqüentemente para poder formular um problema mais preciso de pesquisa ou de criar novas hipóteses. Para Malhotra (2001, p. 106), na pesquisa exploratória as informações necessárias são definidas ao acaso, o processo de pesquisa é flexível e não estruturado, a amostra é pequena, não representativa e a análise dos dados primários é qualitativa. Os resultados geralmente são seguidos por novas pesquisas exploratórias ou conclusivas. Cabe ressaltar que esta se apresenta como uma pesquisa qualitativa, onde, como apontado por Richardson (1989, p. 39), tem como objeto situações complexas de determinado problema, e que esse modelo de pesquisa, entre outros pontos, é utilizado em situações onde observações qualitativas são usadas como indicadores do funcionamento de estruturas sociais.

A notória a limitação de estudos referentes ao tema proposto valorizou a importância da busca por informações, a partir de pessoas que viveram a realidade pesquisada. Dessa maneira, se fez necessário o uso de técnicas de entrevistas para realizar a coleta dos dados. Assim, considerando o objetivo proposto, apontou-se, entre as possibilidades metodológicas, a pesquisa bibliográfica sobre o conceito de tempo livre e a ocupação desse tempo pelo trabalhador da CPEF, além da realização de entrevistas "semiestruturadas" buscando obter informações sobre o entrevistado, sobre os fatos que ele conhece e de seu comportamento (conhecer a opinião do entrevistado, explorando suas atividades e motivações). Esse método de entrevista se caracteriza por seguir um roteiro elaborado previamente, de acordo com os objetivos do estudo. Quanto à técnica, seguimos o modelo de entrevista dirigida, onde as perguntas são precisas, pré-formuladas e seguem uma ordem preestabelecida, permitindo ao entrevistador dirigir o processo, evitando o "desvio" do entrevistado, mesmo que esse tenha maior liberdade em suas respostas (RICHARDSON, 1989, p. 163). Depois de realizadas as entrevistas procederam-se o processo de transcrição e análise.

O roteiro da entrevista foi organizado compreendendo três blocos de questões, de acordo com o objetivo da pesquisa, como o que se apresenta a seguir:

Bloco 1 - trata de questões que envolvem o trabalhador aposentado, com sua antiga profissão, e a imagem que o mesmo tem sobre a Companhia Paulista de Estradas de Ferro (CPEF) e as oportunidades que a empresa oferecia.

Pergunta 1. Quando o Senhor começou a trabalhar na CPEF, quais foram suas funções $e$ por quanto tempo trabalhou lá?

Pergunta 2. Como o Senhor descreve a sua vida como ferroviário, no tempo em que trabalhou na CPEF?

Pergunta 3. Quais eram as oportunidades de lazer, passeios e diversão, para os ferroviários da CPEF, em Rio Claro?

Bloco 2 - nesse bloco são introduzidas questões sobre o Grêmio Recreativo dos empregados da Companhia Paulista de Estradas de Ferro (GRECPEF), a fim de conhecer o envolvimento do entrevistado com o clube.

Pergunta 4. O Senhor é sócio do GRECPEF? Desde quando? Fez parte de alguma diretoria?

Pergunta 5. O Senhor praticava esportes no GRECPEF? Fez parte de alguma equipe?

Pergunta 6. Quem eram os sócios do GRECPEF?

Bloco 3 - as perguntas deste bloco buscam informações sobre a história institucional do GRECPEF e as relações do clube com o Município de Rio Claro.

Pergunta 7. O que o Senhor pode me contar acerca da história do Grêmio?

Pergunta 8. Como o Senhor vê o papel do GRECPEF no esporte de Rio Claro?

Pergunta 9. Como o Senhor descreve a convivência entre os associados do GRECPEF? E do GRECPEF com a cidade?

Pergunta 10. Do seu ponto de vista, quais foram os momentos mais significativos da história do GRECPEF?

A população e a amostra trabalhadas foram definidas visando constituir "redes e colônias" (MEIHY, 1996, p.54), onde a "colônia" pode ser compreendida como um grupo amplo que tenha uma "comunidade de destino", e as "redes" como 
subdivisões significativas da "colônia" (MEIHY, 1996, p.54). Como o ponto central da pesquisa são as relações de lazer e o uso do tempo livre dos ferroviários com o Grêmio Recreativo dos Empregados da Companhia Paulista de Estradas de Ferro (GRECPEF), o clube se apresenta como a "colônia", a comunidade que todos os sujeitos partilham. Dessa forma, a "colônia" da pesquisa é formada por ferroviários do sexo masculino, aposentados pela Companhia Paulista de Estradas de Ferro (CPEF) e que fazem parte do quadro de associados do Grêmio Recreativo dos Empregados da Companhia Paulista de Estradas de Ferro (GRECPEF). A definição da "rede" precedeu de uma análise das possibilidades de obtenção das informações, ou seja, encontrar qual o melhor grupo e em que local estão as melhores pessoas para que se possa colher um maior e melhor número de informações. Porém, durante o desenvolvimento do trabalho notou-se que havia três grupos interessantes para as investigações, ou seja, haveria a possível representação de três "redes".

A primeira "rede" está representada pelas pessoas que estão diretamente ligadas ao GRECPEF e que vivenciam o clube dia a dia. São diretores, conselheiros e funcionários que tem em seu relato informações que valorizam mais as atividades de sua gestão administrativa no clube.

A segunda "rede" é formada por aposentados que freqüentavam a União dos Ferroviários Aposentados (UFA), uma associação fundada em 1951, que tem como objetivo ser uma entidade de apoio social ao ferroviário aposentado, não estando vinculada ao sindicato dos ferroviários e que também não exerce função similar à de um sindicato. O motivo da escolha de uma nova "rede" a partir da UFA vincula-se ao fato de que, na associação, está presente e atuante um grupo de ferroviários aposentados diferentes dos que trabalham diretamente nas atuais atividades administrativas do GRECPEF. No decorrer dos trabalhos ficou evidenciado que os diretores e os participantes mais assíduos da UFA fazem parte de outro grupo político que não mais administra o GRECPEF, mas que participou da construção do clube, no período que se estende entre 1970 e 1990, e, atualmente, se apresenta critico da atual gestão.

A terceira "rede" buscou, através das entrevistas, informações que não caracterizariam discursos políticos da vida do clube, não agregando descrições relacionadas como: quem fez a piscina? Quem reformou o campo de futebol ou demoliu alguma estrutura? Não que essas informações não sejam importantes para a construção da história estrutural e política do GRECPEF, mas essas não são o foco desta pesquisa. Assim, essa "rede" será representada pelos associados que freqüentam o clube diariamente e fazem deste seu meio de lazer.

O que ficou evidenciado após a coleta e análise dos dados foi que as três "redes" se relacionam, estão imbricadas, podendo-se dizer, também, que há apenas uma única "rede", e que essa apresenta facetas que formam as "subredes", pois na diretoria e conselho do GRECPEF, assim como, na diretoria e conselho da UFA e os freqüentadores do clube, os membros têm uma característica em comum: todos são ferroviários aposentados. Tendo claro que a formação imbricada da "colônia", apresenta facetas em seu interior, foram entrevistadas duas pessoas em cada um dos três segmentos claramente definidos, sendo escolhidas aleatoriamente, para representar as "sub-redes". Como é de característica de uma pesquisa exploratória, a amostra é pequena e não representativa. No entanto essa implicação não invalida a pesquisa, em face da carência de estudos sobre o assunto, tendo como interesse dar subsídios para as novas investigações.

Os depoentes que colaboraram com nossa pesquisa receberam, antes de sua entrevista, um termo de consentimento livre e esclarecido, onde os mesmos tomaram conhecimento das pretensões do trabalho e a relação com sua participação. No corpo do trabalho, os depoentes estão identificados por seu primeiro nome, haja vista que os mesmos autorizaram sua publicação. Os entrevistados ${ }^{1}$ podem ser identificados da seguinte maneira:

- Depoente "Antonio" (aposentado em 1966)

- Depoente "Artur" (aposentado em 1974)

- Depoente "Adalberto" (aposentado em 1969)

- Depoente "José Renato" (aposentado em 1994)

- Depoente "Eduardo" (aposentado em 1970)

- Depoente "José Roberto" (aposentado em 1992)

\footnotetext{
${ }^{1}$ As entrevistas utilizadas no presente artigo podem ser encontradas em: VALDANHA, A. A Companhia Paulista de Estradas de Ferro, o Grêmio Recreativo e o Município de Rio Claro: relações de trabalho e lazer - um estudo exploratório. 2007. 116 f. Dissertação (Mestrado em Ciências da Motricidade). Instituto de Biociências - Universidade Estadual Paulista, Rio Claro, 2007. Entrevistas anexadas no trabalho e arquivadas em 6 fitas $k 7$.
} 


\section{Resultados}

\section{CPEF: o trabalho e o lazer do ferroviário}

Todos os entrevistados são funcionários aposentados da Companhia Paulista de Estradas de Ferro (CPEF), sendo que, dos seis depoentes, três deles se aposentaram após a CPEF ser encampada pelo Estado, com o nome de FEPASA, no ano de 1971. Durante as entrevistas, pode-se perceber que esse momento marcou uma passagem nas mudanças da relação da empresa para com o trabalhador, como apontaram em suas falas dois dos entrevistados, como por exemplo, o depoente "José Renato" (aposentado em 1994) ao dizer que sua vida de ferroviário "foi uma vida difícil, porque como a maioria das empresas estatais, também era um tremendo cabide de emprego, nem sempre a dedicação que o funcionário tinha era reconhecida" (informação verbal). $\mathrm{Em}$ contrapartida a essa afirmação, o depoente "Antonio" (aposentado em 1966), afirmou que "na companhia paulista, principalmente o empregado, ele tinha um carinho por aquilo. Ele se considerava como um dono, era um prazer de trabalhar no tempo da companhia paulista" (informação verbal). Apesar dessa controvérsia em relação ao ambiente de trabalho e de apontamentos referentes às extensas jornadas de trabalho, onde se trabalhava dia e noite (Artur, aposentado em 1974), transpareceu ser unânime o orgulho, por parte dos entrevistados, em fazer parte da classe operária dos ferroviários. É importante ressaltar que todos são filhos de ferroviários, como, por exemplo, o caso do depoente "Artur" (aposentado em 1974), que além de seu pai, seu avô trabalhou na CPEF.

O fato de a família passar por gerações trabalhando na Paulista é motivado pela nova organização social e oportunidade de trabalho na zona urbana de Rio Claro. O depoente "Antonio" (aposentado em 1966) afirmou que "na época (década de 40) em Rio Claro era difícil o trabalho..., nós tínhamos três indústrias mais ou menos fortes que era a Companhia Paulista, a Caracu e o Matarazzo" (informação verbal). Essa afirmação é fortalecida por Tenca (2002, p. 245), quando o autor afirma que o salário na empresa era pouco, porém a CPEF sabia que muitos necessitavam e desejavam a estabilidade do emprego na empresa. Isso levou à construção do que o autor chamou de "família ferroviária". A formação dessa comunidade não é fato isolado no momento de construção da modernidade, pelo contrário, muitas empresas fizeram uso da unidade conhecida e vivida na organização comunitária. Assim, a empresa assumiu características paternalistas, dando aos trabalhadores a impressão da organização de uma comunidade privilegiada.

A CPEF não se portou de maneira diferente, promoveu, para seus funcionários, diversos eventos culturais, sociais, esportivos, todos realizados no tempo liberado do trabalhador, fortalecendo, assim, os laços que estes teriam com a empresa, pois os mesmos sentiram-se gratos por trabalharem para um patrão que thes oferecia tantas oportunidades. As famílias se conheciam, se relacionavam e isso traria um enorme sentimento de bem-estar, fazendo com que todos os funcionários se sentissem como parte de um único mundo, um único laço, uma única e grande família. Nesse caso, a atuação da CPEF, como afirma Garcia (1992), era através do cineminha da Paulista, do teatro ferroviário e do Grêmio Recreativo dos Funcionários da Companhia Paulista de estradas de Ferro de Rio Claro (GRECPEF)

Outra mudança característica dos tempos modernos é a relação do trabalhador com o processo de aprendizagem do trabalho. O trabalho era aprendido na família, de geração para geração e, com as transformações ocorridas na organização social de Rio Claro, com a chegada da CPEF, ocorrem às mudanças no sistema de aprendizagem do trabalho. É a partir da implantação das oficinas de trens e vagões que se dá o desenvolvimento do Curso de Ferroviários da CPEF, como aponta Tenca (2002), responsável por fazer com que muitos jovens contratados passassem pelos bancos da escola, principalmente nos cursos de marcenaria e mecânica.

Todos os entrevistados passaram pelo curso ferroviário, que, na década de 40, conforme apontado pelo depoente "Antonio" (aposentado em 1966), passou a ser conhecido como SENAI da Companhia Paulista de Estradas de Ferro (informação verbal). A qualificação da mão de obra era feita durante o envolvimento do funcionário com a produção, a partir de conhecimentos prévios que o mesmo havia adquirido na vivência com seus familiares e com o curso técnico. Segundo o depoente "Artur" (aposentado em 1974), filho e neto de ferroviário, 
sua primeira profissão dentro da CPEF foi de rebitador, ocupação que o mesmo aperfeiçoou com a prática do trabalho, após ter passado pelo curso da Paulista (informação verbal).

Com a criação de uma Escola de Formação Profissional, o ensino passa a ser institucionalizado e o ambiente da comunidade deixa de ser o local de aprendizagem. Como afirmou Barata (2004), para compreender, o conhecimento do "fazer saber" foi substituído pelo "saber fazer". As alterações no processo de aprendizagem do ofício, ocorridas na CPEF em meados da década 1930, como afirma Tenca (2002, p. 244), fazem parte de um processo de formação profissional da empresa, que se constitui em elementos de prática racionalizadora de organização do trabalho.

Sentir-se como parte de uma única família, ou ainda, conseguir com que todos da família (filho, pai, avô, tios...) trabalhassem na Paulista, como era preterido por todos, aponta Tenca (2002, p. 260), poderia ajudar a suportar as extensas horas da jornada de trabalho, que ultrapassavam às 8 horas diárias, incluindo os sábados. Isso fazia com que o tempo liberado, livre das obrigações de trabalho, um tempo onde podia estar presente o lazer, como afirma o depoente "José Roberto" (aposentado em 1992), fosse reduzido às horas dos finais de semana (informação verbal).

Nas entrevistas, ficou evidenciada a influência da CPEF nas atividades de lazer de seus funcionários, principalmente no momento em que é deixado claro que o GRECPEF é um clube construído com capital e apoio da empresa, o que fez do mesmo o centro das práticas de lazer e interação social entre as famílias dos ferroviários. O depoente "José Roberto" (aposentado em 1966) aponta o Grêmio Recreativo como sua principal fonte de lazer:

$\mathrm{Na}$ época passava meu tempo de fora do trabalho quase todo no grêmio, na pista de atletismo, campo de futebol, quadra de bocha e basquete, e depois que foi construída a piscina, aí então passou a melhorar ainda o lazer. Fora eu, a maioria, boa parte dos ferroviários, principalmente jovens naquela época freqüentava isso aí. $E$ os bailes né, que era o mais gostoso (informação verbal). ${ }^{2}$

\footnotetext{
${ }^{2}$ As entrevistas utilizadas no presente artigo podem ser encontradas em: VALDANHA, A. A Companhia Paulista de Estradas de Ferro, o Grêmio Recreativo e o Município de Rio Claro: relações de trabalho e lazer - um estudo exploratório. 2007. 116 f. Dissertação (Mestrado em Ciências da
}

Os entrevistados apontaram, em diversos momentos, a importância do GRECPEF, não somente para seu próprio tempo livre, mas também, para o de sua família, quando falaram sobre a alegria dos bailes promovidos e as oportunidades de seus filhos aprenderem modalidades esportivas dentro do clube.

Uma questão que não ficou muito clara, e que ganhou visibilidade com a análise dos dados, são as mudanças de comportamento, tanto da Paulista, quanto do ferroviário, após a empresa ser encampada pelo Estado. Esse momento está vinculado a uma transformação que ocorreu na estrutura organizacional da empresa e, por conseqüência, no apoio e incentivo destinado ao GRECPEF. Essa mudança, aparentemente, gerou insatisfações dos trabalhadores em relação a seu trabalho e também alterações na organização do clube.

Sem o apoio da Paulista, o Grêmio passa a buscar um aumento em seu quadro de associados, a partir de pessoas que não são ferroviários, os conhecidos sócios de categoria "B". O depoente "José Renato" (aposentado em 1994) o ultimo dos entrevistados a se aposentar, afirmou que,

no final da década de 80, a empresa cedeu aos
ferroviários um espaço que antes pertencia ao
SENAl ferroviário, para que fosse construída
uma área social com jogos de salão, campo de
futebol, vôlei de areia e sauna (informação
verbal). ${ }^{3}$

Talvez, essa luta dos ferroviários por um novo espaço de interação, que fosse destinado somente à categoria, seja uma resposta ao crescimento e posterior superioridade do numero de sócios do GRECPEF que não fossem ferroviários.

\section{GRECPEF: CPEF, o ferroviário e o não ferroviário}

Em sua ata de fundação, o Grêmio Recreativo dos Empregados da Companhia Paulista de Estradas de Ferro (GRECPEF) apresentou 5 nomes, sendo três ferroviários, com destaque para o engenheiro chefe da Companhia Paulista de Estradas de Ferro (CPEF) Adão Gray, e dois comerciantes da cidade, Julio Marasca e Timoni.

Motricidade). Instituto de Biociências - Universidade Estadual Paulista, Rio Claro, 2007. Entrevistas anexadas no trabalho e arquivadas em 6 fitas $k 7$.

${ }^{3}$ Ibid., 2007. 
A partir de consulta nas atas do clube e depoimentos colhidos nas entrevistas, não fica clara a situação das pessoas que não faziam parte do quadro de funcionários da CPEF frente ao GRECPEF, até 1963. Apesar de ter em sua ata de fundação a presença de membros da sociedade em geral, não foram encontrados registros esclarecedores sobre a possibilidade de associação ou não dessas pessoas, em virtude de um incêndio que ocorreu na secretaria do clube em 1911, quando, perderam-se todos os registros entre os anos de 1896 e 1910. Em sua entrevista, o depoente "Artur" (aposentado em 1974) sugere que, antes de 1963, data que marca uma alteração no estatuto do clube, "não havia diferenças entre os grupos, ferroviários e não ferroviários representados por sócios intitulados de categoria A e categoria B" (informação verbal). Ambos os grupos teriam direitos iguais quanto a uso das instalações, voto, elegibilidade e participação nas comissões, ficando segmentados apenas no valor cobrado das mensalidades, onde a categoria B teria valores mais elevados.

O que há de fato nos registros do clube é o novo estatuto do GRECPEF, de 1963, que apresenta e define as categorias "A" e "B" da associação. O sócio ferroviário, nos dias atuais, em sua maioria aposentada, tem total liberdade de ação política no clube, enquanto que os associados que não são ferroviários, além das mensalidades mais elevadas, não podem participar de nenhuma diretoria ou comissão. Da mesma forma, o não ferroviário também não tem direito a voto para a eleição das mesmas. É importante destacar que o quadro de associados do Grêmio, como afirmou depoente "José Renato" (aposentado em 1994), envolve quase 30 mil pessoas do Município de Rio Claro, sendo que, dessas, 10 mil representam a categoria "A" e desses, cerca de 9 mil são sócios remidos, ou seja, não pagam mais mensalidade e não contribuem para a receita do clube (informação verbal). Cabe aqui evidenciar que todos os depoentes desse estudo fazem parte dessa categoria.

Da sua fundação até o começo da década de 70, o clube contou com o apoio da CPEF, como aponta o depoente "José Renato" (aposentado em 1994), ao afirmar que:

A Companhia Paulista, na época, adquiriu o terreno e fundou o Grêmio em conjunto com alguns ferroviários, e depois da fundação ela passou a ajudar muito. Porém, os funcionários normalmente terminavam o expediente no trabalho, e iam ao clube para trabalhar, fazer as obras que eram necessárias para deixar o clube em condições de uso (informação verbal). ${ }^{4}$

O depoente "Antonio" (aposentado em 1966) reforçou a idéia apresentada e ainda enfatizou o envolvimento da Paulista, não somente com o GRECPEF, mas também, com o Município de Rio Claro, quando afirma que

A ferrovia era quem sustentava o Grêmio, era
justamente a Ferrovia. A ferrovia não só
sustentava o Grêmio como até a Santa Casa de
Rio Claro. Mandando, na hora que precisasse
fazer algum reparo, em fim, a manutenção,
mandava ferroviário pra lá. Era o pessoal da
Ferrovia que dava manutenção no Grêmio.
(informação verbal).

Essa mudança nas relações entre 0 GRECPEF e a CPEF terminou no inicio da década de 70, momento em que a CPEF foi encampada pelo Estado. As entrevistas apontaram que o fim dos auxílios da empresa na manutenção, no empréstimo de maquinários e na doação de materiais ao clube aconteceu devido a uma divergência política entre a administração do clube e o engenheiro chefe da empresa. Esse momento foi registrado num dos trechos da entrevista do depoente "José Renato" (aposentado em 1994):

Depois de 1970, quando houve aqui uma eleição, e normalmente os presidentes aqui eram indicados pelo gerente das oficinas, aí entra um pouco na política. Naquele ano não ganhou o presidente indicado pelo chefe das oficinas, na época o engenheiro Sergio Bastos, não foi o indicado dele que ganhou, e em função disso os laços foram rompidos, o cordão umbilical foi cortado. O Grêmio passou então a ter vida própria, sem nenhuma colaboração direta da Companhia Paulista. (informação verbal)

Porém, em relação à associação do ferroviário ao clube, as entrevistas não apontaram nada que levasse a um caminho de compreensão que sugira obrigatoriedade por conta da CPEF, o que se pode constatar nos depoimentos é que os maiores incentivadores do clube eram os próprios ferroviários, que realizavam propaganda verbal, como diz o depoente "Artur" (aposentado em 1974), na intenção de incentivar os colegas (informação verbal). Observando a evolução do quadro de sócios do clube, ficou evidente que foi através do crescimento e desenvolvimento das estruturas que levou ao aumento do número de

\footnotetext{
${ }^{4}$ Ibid., 2007.
} 
associados. Porém, os que eram associados, independente da época ou das estruturas, faziam do clube seu objeto de uso no tempo livre.

\section{GRECPEF: o clube, a cidade e o esporte}

Fundado em 05 de Agosto de 1896, o Grêmio Recreativo dos Empregados da Companhia Paulista de Estradas de Ferro (GRECPEF), se apresenta como o principal clube esportivo e social na cidade de Rio Claro. Esta condição foi alcançada ao longo de sua história, quer seja por ser o local de atendimento ao tempo livre do trabalhador rio-clarense, inicialmente representado pelos funcionários da Companhia Paulista de Estradas de Ferro, a maior parte da população de Rio Claro no início do século XX, (DINIZ, 1973), quer seja ainda por suas influências no desenvolvimento do esporte na cidade, que podendo ser apontado como exemplo, a fundação do Rio Claro Futebol Clube, em 1909.

O depoente "Artur" (aposentado em 1974) apontou, em sua entrevista, que, muitas vezes, o clube cedeu seu campo de futebol para a equipe do Rio Claro Futebol clube treinar (informação verbal). Os indícios dessa parceria ficam apresentados pela fala do depoente "José Roberto" (aposentado em 1992), ao colocar que a equipe de futebol foi criada em 1909, com apoio da CPEF, onde muitos dos jogadores do Rio Claro eram Ferroviários, e às diversas vezes a ferrovia até mesmo contratava funcionários que fossem jogadores de futebol para que esses jogassem no Rio Claro Futebol Clube (informação verbal).

O interesse pelo futebol tem relação com o modelo esportivista de ocupação do tempo livre, que surge na Inglaterra após a revolução Industrial, como uma maneira de reproduzir os ideais de divisão do tempo e metas próprios da nova organização social. Como a CPEF foi formada por capital do governo e administrada por ingleses, apesar de não haver relatos ou documentos que afirmem, pode-se sugerir que esse incentivo teve possíveis relações com esse modelo de organização do tempo fora do trabalho e, também, com um possível interesse, por parte dos ingleses, de trazerem sua cultura esportiva, no caso o futebol, e, possivelmente, o tênis, já que, segundo o GRECPEF foi o primeiro clube da cidade a contar com uma quadra de Tênis, em 1920 (VALDANHA, GNECCO, 2004).
As relações do GRECPEF com o Município de Rio Claro são significativas, quando levada em consideração a parcela da população que é atendida, pois o clube que tem cerca de $30 \mathrm{mil}$ associados distribuídos em suas categorias, o que representa $1 / 6$ da população da cidade. As competições promovidas no clube não envolvem somente seus associados, mas também, lojas do comércio, que patrocinam as equipes. $\mathrm{O}$ depoente "José Renato" (aposentado 1994), em sua entrevista, afirma que

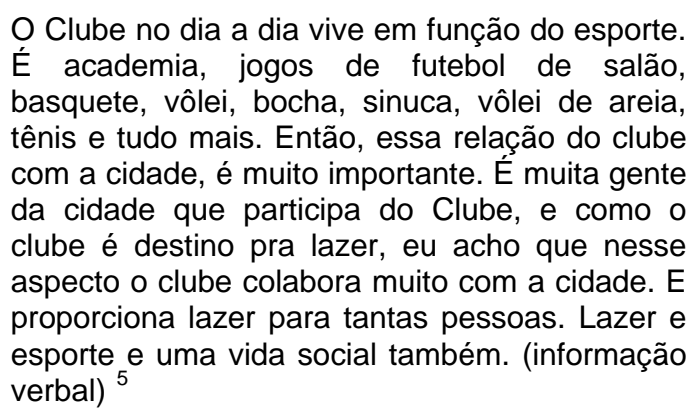

Em entrevista, o depoente "Antonio" (aposentado em 1966), ao relembrar o período de 1947, no qual se associou ao GRECPEF, lembrou que, no Município de Rio Claro, não havia outro clube que oferecesse práticas esportivas. O mesmo colocou, ainda, que existiam outras sociedades, mas dançantes, como a Filarmônica e o Grupo Ginástico (informação verbal).

\section{Discussão}

Uma mudança na sociedade compreende uma mudança de valores. A passagem para o modo de produção Industrial foi determinante para o desenvolvimento urbano, em detrimento do setor agrário, momento que marca a separação do trabalho e não trabalho, ambos tendo o "tempo" como principal relação para sua existência. De acordo Marcellino (1994), o aspecto tempo representa um dos componentes da dinâmica produtora do lazer, possuindo traços específicos da civilização nascida da revolução industrial, caracterizada pelo fato do sistema social ter, no seu epicentro, a produção em grande série, de bens materiais, através da indústria.

O aumento da produção, proporcionado pelo desenvolvimento de novas tecnologias, agregado às lutas de trabalhadores por menores jornadas de trabalho, proporciona alterações na organização diária das pessoas (CAMARGO,

\footnotetext{
${ }^{5}$ Ibid., 2007.
} 
1986), promovendo o crescimento do tempo liberado do trabalho (DUMAZEDIER, 1975).

No tempo liberado estão compreendidas atividades que não fazem parte do tempo de trabalho, produtivo e racionalizado pela cultura industrial (DUMAZEDIER, 1975). Esse tempo, liberado, é destinado para que sejam cumpridas outras obrigações, que antes do processo de Revolução Industrial, já faziam parte do cotidiano da vida na comunidade. São atividades sociais, religiosas, políticas e familiares, que, antes da divisão temporal evidenciada pela modernidade, misturavam-se com o tempo de trabalho, haja vista que este era determinado por ciclos e ritmos naturais (CAMARGO, 1986).

O modelo de organização social moderno, não apenas limita o tempo de trabalho e o tempo destinado para outras obrigações, mas também, abre espaço para o desenvolvimento de um novo momento, outro tempo, diferente dos outros, caracterizado pelo descompromisso, conhecido como tempo livre, e nele podem estar inseridas as atividades de lazer (DUMAZEDIER, 1975). Para Marcellino (1994), o lazer não é ociosidade, não suprime o trabalho, o pressupõe. Corresponde a uma liberação periódica do trabalho.

$\mathrm{Na}$ modernidade, os "momentos livres", mesmo pertencendo ao trabalhador, são determinados pela relação capital-capitalismo. Novos valores começam a se estabelecer entre trabalho e tempo livre do trabalho. As atividades são sistematizadas e trazem em seu interior valores que reproduzem os modelos de produção. Isso faz com que as empresas comecem a oferecer a seus funcionários formas para fazer uso de seu tempo livre.

No Município de Rio Claro, esse quadro teórico, representativo das mudanças de valores da modernidade, encontra fundamento no âmbito da relação entre a Companhia Paulista de Estradas de Ferro (CPEF) e a cidade. Os trilhos da ferrovia marcam o início da urbanização e da produção fabril, dando base para as alterações na organização social e de relacionamento dos trabalhadores com seu tempo.

A população rio-clarense vai, aos poucos, se tornando parte da CPEF, a maior empregadora do Município, e a empresa aproveita essa dependência para construir o que Tenca (2002, p. 245) chamou de "família ferroviária", unindo parentes, amigos e, até mesmo, desconhecidos, em um único laço, criando, assim, a sua própria comunidade. Essa é uma característica tão forte, que marca gerações de trabalhadores ferroviários da cidade, como evidenciado pelas entrevistas dessa pesquisa.

Para promover essa inter-relação entre os funcionários e seus familiares, a CPEF promovia piqueniques, seções de cinema e implantou uma cooperativa. No entanto, o principal meio para essa interação foi, provavelmente, o Grêmio Recreativo dos Empregados da Companhia Paulista de Estradas de Ferro (GRECPEF), sendo que esse unia os trabalhadores, não somente em atividades de lazer, mas também, em sua construção predial. Pode-se sugerir que esse envolvimento fez com que o trabalhador da CPEF não se limitasse a sentir-se satisfeito pela empresa lhe proporcionar um espaço social de lazer, mas também, faz com que esse se sinta importante e, de certa forma, proprietário do local, sendo que este, em suas horas livres, ajudava a erguer as paredes do clube.

Durante a construção desse trabalho encontramos no GRECPEF um ícone para as atividades de tempo livre do trabalhador ferroviário e do não ferroviário. Ao longo de seus 112 anos, o clube permanece com raízes ferroviárias, sendo um ponto de encontro para gerações de trabalhadores da CPEF e da FEPASA, mas, desde os anos de 1960, o crescente número de associados que não têm relação com a ferrovia ganha espaço e leva para outros lugares do Município rastros da cultura "Gremista" (como é conhecido o associado do clube). Esse fato atual, agregado à construção histórica da sociedade rio-clarense, sugere que o GRECPEF tem significativa importância e influência na construção de uma cultura de tempo livre em Rio Claro.

\section{Conclusão}

No presente artigo buscamos resgatar na memória do ferroviário aposentado, as relações que esse tinha com a CPEF e com o GRECPE, bem como, as relações entre CPEF, o GRECPEF e o Município de Rio Claro, através de entrevistas possibilitariam uma reinterpretação dos fatos encontrados na literatura referente ao tema e, até mesmo, dos documentos e registros encontrados. Ao tomar contato com a grandeza do objeto de estudo e a pouca produção acadêmica 
diretamente relacionada, ficou evidente que seria preciso demarcar os caminhos que limitam o objeto de estudo, bem como, pontuar as possíveis hipóteses que deveriam ser aprofundadas. Para tais pretensões optamos por uma pesquisa exploratória, sendo que essa comportaria nossas ambições no trabalho.

A principal hipótese levantada após a realização do estudo refere-se às mudanças proporcionadas pela instalação dos trilhos da CPEF e, posteriormente, das oficinas da empresa e a sua relação com o uso do tempo liberado e livre do trabalhador da empresa, haja vista que a CPEF, desde sua criação, se apresentou como uma empresa transformadora. Sua fundação tinha um objetivo transformador, que era de sanar as necessidades dos produtores cafeeiros do interior paulista. Nos municípios que a empresa se instalou, tendo Rio Claro como exemplo, a empresa promoveu diversas alterações na organização social e ressignificou a maneira com que o trabalhador lidava com sua mão de obra e seu tempo diário.

Com as mudanças, enraizadas na nova cultura de trabalho que floresce do seio da revolução industrial, desenvolve a idéia de tempo liberado, e com isso surgem necessidades de ocupação para esse tempo, até então desconhecido. A própria revolução industrial se incumbiu de propor atividades para esse novo tempo e essas nasceram sob a luz dos objetivos da produção fabril. A CPEF não se portou diferente, provavelmente, por ser uma empresa gerenciada por ingleses e esses, além de serem os pioneiros do processo de revolução industrial, também são os inovadores das atividades de ocupação do tempo liberado. É no âmbito desse processo que a CPEF investe e apóia a formação de um clube esportivo para seus funcionários, o Grêmio Recreativo dos Empregados da Companhia Paulista de Estradas de Ferro (GRECPEF).

O clube ganha destaque em seus anos de atividade e passa a fazer parte do dia-a-dia do Município. A principal razão para se crer que o GRECPEF é provavelmente o maior responsável pela influência na formação da cultura de uso do tempo livre do trabalhador rio-clarense é a de que, por muito tempo, a classe ferroviária representou a maioria da população urbana ativa de Rio Claro e, atualmente, o clube tem, em seu quadro de associados, 1/6 da população da cidade.

Acreditamos que, após as investigações deste trabalho, foi levantada a relevância que essa temática tem, não apenas para o Município de Rio Claro, ou para o GRECPEF e a CPEF, mas, tem valor significativo para a ampliação dos conhecimentos da Educação Física e sua área de atuação, possibilitando que sejam conhecidas as raízes da atuação profissional de uma parcela significativa dos graduados na área. Entre as propostas para novos trabalhos, acreditamos ser importante a sugestão de uma coleta maior de entrevistas para a uma formação mais sólida da memória do ferroviário aposentado e, também, a elaboração e construção de um memorial, que organize e apresente os documentos, atas e fontes iconográficas do GRECPEF, a fim de preservar e apresentar a memória material do clube.

\section{Referências}

BARATA, J. N. Camponeses, pedreiros e educadores: limites explicativos de teoria e prática. In:__, Educação Profissional: saberes do ócio ou saberes do trabalho? São Paulo: SENAC, 2004.

BILAC, E. D. Famílias de Trabalhadores: Estratégias de Sobrevivência. São Paulo: Símbolo, 1978.

CAMARGO, L.O.L. O que é lazer. S. Paulo: Brasiliense, 1986.

DEAN, W. Rio Claro: um sistema brasileiro de grande lavoura - 1820 - 1920. Rio de Janeiro: Paz e Terra, 1977.

DINIZ, D. Rio Claro e o Café: desenvolvimento, apogeu e crise (1850 - 1900). Tese (Doutorado em História) - Departamento de Ciências Sociais, Faculdade de Filosofia, Ciências e Letras de Rio Claro, Rio Claro, 1973.

DUMAZEDIER, J. Questionamento teórico do lazer. Porto Alegre: PUC-RS, 1975.

GARCIA, L. B. R. Rio Claro e as oficinas da Companhia Paulista de Estrada de Ferro: trabalho e vida operária 1930 - 1940. 1992. Tese (Doutorado em História)- Instituto de Filosofia e Ciências Humanas, Universidade de Campinas, Campinas, 1992.

MALHOTRA, N. Pesquisa de marketing: uma orientação aplicada. Porto Alegre: Bookman, 2001. 
MARCELLINO, N. C. Tempo e Atitude, Ainda sobre tempo e atitude, O conteúdo do lazer \& Atividade e passividade. In_Capacitação de animadores sócio-culturais. Campinas:

Unicamp, FEF, DEL; Brasília: MED, SEED,PFDC, 1994.

MARRACH, S. A. Visão do Mundo dos

Ferroviários Aposentados. 1983. Dissertação (Mestrado em História), Pontifícia Universidade Católica de São Paulo, Campinas, 1983.

MEIHY, J. C. S. B. Manual de historia oral. São Paulo: Loyola, 1996.

QUEIROZ, O. T.M.M. O desenvolvimento do lazer em Rio Claro. Rio Claro, 1986. 175p. (Trabalho de Graduação em Geografia e Estágio de Iniciação Científica apresentado ao Instituto de Geociências e Ciências Exatas, UNESP, Campus de Rio Claro).

RICHARDSON, R. J. Pesquisa social: métodos e técnicas. São Paulo: Atlas, 1989.

SANTOS, F. A. Rio Claro: uma cidade em transformação (1850 - 1906). São Paulo: Anablume - FAPESP, 2002.

SELTTIZ, C.; JAHODA, M.; DEUSTSCH, M.; COOK, S. W. Métodos de Pesquisa nas Relações Sociais. São Paulo: Heder, 1967.

TENCA, A. Nos trilhos da memória: racionalização, trabalho e tempo livre nas narrativas de velhos trabalhadores, ex-alunos do curso de ferroviários da companhia paulista de estradas de ferro. Tese (Doutorado em Educação), Faculdade de Educação, Universidade de São Paulo, São Paulo, 2002.

VALDANHA, A.; GNECCO, J. R. Rio Claro: cidade do esporte. In: DA COSTA, L.P., Atlas do esporte no Brasil: Atlas do esporte; educação física e atividades físicas de saúde e lazer no brasil. Rio de Janeiro: Shape, 2005.

Esse trabalho é derivado da Dissertação intitulada "A COMPANHIA PAULISTA DE ESTRADAS DE FERRO, O GRÊMIO RECREATIVO E O MUNICIPIO DE RIO CLARO: RELAÇÕES DE TRABALHO E LAZER - UM ESTUDO EXPLORATÓRIO", apresentada ao Instituto de Biociências do Campus de Rio Claro, Universidade Estadual Paulista, como parte dos requisitos para obtenção do título de Mestre em Ciências da Motricidade (Área de Pedagogia da Motricidade Humana)

\section{Endereço:}

Américo Valdanha Netto

Avenida 7, 1502, Jardim Claret

Rio Claro-SP

13503-270

e-mail: valdanha@uol.com.br

Recebido em: 18 de junho de 2008.

Aceito em: 24 de março de 2010.

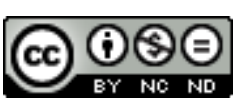

Motriz. Revista de Educação Física. UNESP, Rio Claro, SP, Brasil - elSSN: 1980-6574 - está licenciada sob Licenca Creative Commons 